\title{
Individualized and Depoliticized: A Study of Chinese Blogosphere in Singapore
}

\author{
Carol Soon*, Jui Liang Sim**
}

*Institute of Policy Studies, National University of Singapore, 1C Cluny Road House 5 Singapore 259599, carol.soon@nus.edu.sg, +65 6516 8372, **Institute of Policy Studies, National University of Singapore, $1 C$ Cluny Road House 5 Singapore 259599, sim.juiliang@nus.edu.sg, +65 65165603

Abstract: Research on new media such as blogs examines users' motivations and gratifications, and how individuals and organizations use them for political participation. In Singapore, political blogs have attracted much public scrutiny due to the bloggers' online and offline challenges of official discourse. While previous research has established the political significance of these blogs, extant scholarship is limited to blogs written in the English language. Little is known about blogs maintained by the Chinese community, the largest ethnic group in multiracial Singapore. This study is a first to examine this community and the space they inhabit online. Through web crawling, we identified 201 Chinese-language blogs and through content analysis, we analysed if Chinese bloggers contributed to public debates and used their blogs for civic engagement. Their content, motivations for blogging in the language, hyperlinking practices and use of badges indicated that Chinese bloggers in Singapore do not use blogs for political participation and mobilization, but are individualized and a-politicized. We discuss possible reasons and implications in this paper.

Keywords: new media, blogs, Chinese, Singapore, civic engagement

Acknowledgement: This study is part of a research project by the Institute of Policy Studies on blogs written in three different vernacular languages (Chinese, Bahasa Malayu and Tamil).

\section{Introduction}

To date, existing research on new media-use takes on four main trajectories: the uses and gratifications which motivate adoption, the implications of new media use on deliberation, civic engagement and collective action, and how new media facilitates horizontal (citizen-to-citizen) and government-citizen communication. In Singapore, public discourse surrounding blogs focuses on those written in English, the country's lingua franca. Since Singapore's independence, the English language has played an economic and social role - it is used as a language of business and is the common denominator that connects different ethnic groups. In recent years, what are commonly known as "socio-political blogs" (those with analyses and commentaries on social, economic and 
political issues related to Singapore) have received much attention from policymakers, the mainstream media and the general public.

Several of these political blogs such as The Online Citizen (TOC), The Independent Singapore, Temasek Emeritus Review and The Breakfast Network ${ }^{1}$ have gained many "eyeballs" and are well-known for their critiques of government policies and the ruling party (People's Action Party or PAP). In addition to being outlets for self-expression, these blogs reach out to different communities of interest and provide spaces for like-minded people to connect to one another. Some bloggers have visible offline personas and are known for their activist work in different domains such as anti-censorship, migrant workers' welfare and lesbian-gay-bisexual-transsexual rights.

While much of the current debate focuses on English-language blogs (henceforth referred to as English blogs) and their impact on Singapore's society, scant attention has been given to nonEnglish blogs. This is despite Singapore being a multi-ethnic society where the government has implemented a bilingual language policy that requires students to take English as the first language and their designated mother tongue language ${ }^{2}$ as a second language. This study examines the use of blogs by the largest ethnic community, the Chinese. We focus on blogs written in the Chinese language (henceforth referred to as Chinese blogs). Besides being the largest ethnic group in Singapore, their political history involving confrontations with the state has been a popular topic of study by historians. First, we identify the salient characteristics of the Chinese blogosphere through a baseline analysis, a first step to charting an unknown territory. Second, we assess if and to what extent there is a politicization of Chinese blogs, specifically if Chinese bloggers use blogs to promote political causes, build networks and forge a collective identity among the Chinese community. We also discuss their political and societal implications. By studying the development of new media use in vernacular languages, this paper fills the gap in existing research, which typically focuses on new media use in the lingua franca of any society or community.

${ }^{1}$ The site ceased operation in late 2012 when the editor decided not to register with the Media Development Authority which regulates the online space.

${ }^{2} \mathrm{~A}$ mother tongue is the language of an ethnic group. There are three official mother tongues in Singapore Chinese for the Chinese, Bahasa Melayu for the Malays and Tamil for the Indians. Non-Tamil Indians have the option of choosing a non-Tamil Indian Language such as Bengali, Gujarati, Hindi, Punjabi or Urdu. 


\section{Blogging Together and Web Action}

Research on blogging has come a long way, the first foray being the analysis of uses and motivations behind blogging (see for example, Herring, Scheidt, Bonus \& Wright, 2004; Nardi, Schiano, Gumbrecht \& Swartz, 2004). Earlier studies have shown that blogging is driven by the need for self-expression and social connection. Personal-type journal blogs are the most prevalent and are used by bloggers to "report on their lives and share their inner thoughts and feelings" (Herring, Scheidt, Bonus \& Wright, 2004, p.6). Studies have also shown that blog networks have small-world and scale-free characteristics similar to those of real-world networks (Fu, Liu \& Wang, 2008; Soon \& Cho, 2011). However, it soon became evident that blogs are becoming a new political force. Unlike traditional broadcast and commercial networks that place and frame predetermined issues on the national agenda, bloggers function as grassroots intermediaries. They accord visibility to an issue if they deem the issues relevant to different publics and, in the process, reframe the issues, hence ensuring that everyone (versus those in control of media) has a chance to be heard (Jenkins, 2006).

Jenkins described blogs as a form of egalitarian grassroots movement that "spoils the American government" and contributes to a new form of media system as bloggers share and scrutinize available information. Observations of how bloggers are shaping the political landscape are not limited to Western countries. Bosch's (2010) analysis of South African political blogs and citizen journalism sites found that bloggers placed themselves in authoritative positions in the area of social commentary and actively influenced opinions. In Malaysia, the blogosphere was rife with political discussions and outright criticisms about the government and its alleged (mis)management of the country's economy. This supposedly culminated in the unprecedented gain of seats by opposition parties in the 222-member Parliament during the general elections in 2008 and undermined the ruling party's grasp on national politics. During the aftermath of the elections, then Malaysian Prime Minister Abdullah Badawi admitted that the government's failure to tap into the blogosphere contributed to the election outcome.

Another area of research pertains to the networking effects of Internet technologies and the establishment of online communities. The instantaneity, reach, and interactivity of computermediated-communication (CMC) makes it possible for people who have a similar ideology or grievances to converge online with ease and speed, hence leading to quick formation of collectives driven by shared goals (Ayers, 2003; McCaughey \& Ayers, 2003). Moreover, links among different protest organizations and the ability to circumvent traditional gate-keeping structures accorded by the Internet make it possible for concerned individuals and groups to unleash a collective and relentless protest (Gurak \& Logie, 2003). Online social network studies in the Singapore context have established that bloggers demonstrated political affinity with others who have a similar ideology through their hyperlinking practices (Soon \& Cho, 2011; Soon \& Kluver, 2007).

The Internet also facilitates the formation of collective identity which is integral for new social movements. Buechler (1993) argued that "for many mobilizations, the most central process is the social construction of a collective identity that is symbolically meaningful to participants and that logically precedes meaningful calculation of the costs and benefits of joining in the collective 
action" (p.228). A collective identity is a manifestation of group attributes and member similarities at a social context and plays a role in effecting the success of a movement. This is because shared frames help movement organizers recruit, mobilize and sustain members (Adams \& Roscigno, 2005). One key dimension of collective identity is the presence of a shared consciousness. Commonality facilitates the cultivation of a shared consciousness and solidarity among members in a group - whether based on similar values, goals, ethnic background or nationality - and fosters a sense of "we".

Studies have shown how digital networks enhance the growth of issue-based movements by allowing people from diverse backgrounds and residing in geographically dispersed locations to converge in cyberspace and cultivate a shared or collective goal. Diani (2000) argued that CMC plays an instrumental role in social movement networks as it strengthens "identities and solidarities among their members by increasing the rate of exchange between geographically very distant activists and organizations, and therefore the density of what is, however, a very peculiar constituency" (p.395). Drawing from her work in media anthropology, Madianou (2005) theorized that technology does not create identity but rather, enables an identity to emerge through the creation of communicative spaces that are both inclusionary and exclusionary. For example, Iranian women through their blogs exchanged intimate thoughts "in a society where women had no public forum, no opportunity to express themselves" (Amir-Ebrahimi, 2008, p.93).

In Singapore, the World Wide Web has created an alternative space for concerned individuals to access non-mainstream perspectives and discuss political, economic and social issues (Ho, Baber \& Khondker, 2002). Online discourse has also begun to spill over to the real world. In 2008, a group of bloggers who called themselves Bloggers 13 came up with a proposal calling for deregulation of the Internet. TOC conducted street polls and held talks at the Speakers' Corner to reach out to the masses ${ }^{3}$. Existing research has established how the Internet enables like-minded veteran and fledgling activists to connect in cyberspace and strengthens the sense of collective identity and impetus to take part in collective action (George, 2006; Ibrahim, 2009; Skoric \& Ng, 2009; Soon, 2013; Soon \& Cho, 2014; Soon \& Kluver, 2014). Through in-depth interviews with 26 activist bloggers in Singapore, Soon (2013) found that activist bloggers used Internet technologies to negotiate institutionalized constraints and overcome challenges posed by collective incentives, structural proximity and structural availability. A shared consciousness of being part of a larger "socio-political" blogging community, distinct blogging practices and the articulation of a common adversary (the ruling party and mainstream media) defined the collective identity shared by activist bloggers and fostered solidarity (Soon \& Kluver, 2014).

This section has established that irrespective of the country of origin of existing research, bloggers have the capacity to act in concert with one another in order to exert a larger collective impact. To contextualize our research agenda, the next section presents the historical and cultural developments which have influenced the Chinese community in Singapore.

3 TOC was subsequently gazetted as a political association by the government in 2009 . 


\section{Being Chinese in Singapore}

Singapore has frequently been described as an immigrant society. As a British colony and trading port, migrants from China and India who came to seek work eventually sank roots alongside the indigenous Malay community. Today, Singapore remains a multi-ethnic society: $74.1 \%$ of Singapore residents are Chinese, with the remaining 13.4\% Malays, 9.2\% Indians and 3.3\% "Others" (i.e., the last group comprising people of mixed-heritage) (Census of Population 2010, Department of Statistics Singapore). Among the ethnic Chinese population, there are several dialect-speaking Chinese subgroups, with Hokkien, Teochew, Cantonese and Hainanese being the main ones. Research on governance in Singapore has highlighted the prevalence of pragmatism in the government's ruling ideology (Chua, 1985; Hill \& Lien, 1995). Such pragmatism extends to the country's language and ethnic policy (Tan, 2006); an approach that is informed by the intersection of historical circumstances as well as political, economic and social imperatives. When Singapore gained independence in 1965, its leaders displayed sensitivity towards its neighbors - none of whom had a Chinese-majority population - by de-emphasizing its "Chinese-ness" (Tan, 2002). This, with the government's strategy to build a multiracial state, develop a Singaporean identity and protect the special position of the indigenous Malays, led to the recognition of English, Mandarin, Tamil and Malay as official languages, with the appointment of English as the language of government, administration and commerce (Tan, 2006).

At the height of decolonization between the late 1940s and mid-1960s, many Chinese school students were involved in student and trade union activities (Kwok \& Chia, 2012). Their identities and world views were intertwined with mainland China, shaped by historical events such as the May Fourth Movement of 1919 and the civil war of 1949. While many of the Chinese-educated students in Singapore were involved in leftist politics, not all were solely leftist or China-oriented as many were influenced by the idea of a Malayan nationalism. The protests that these students took part in were often in response to policy changes made by the colonial government such as the dissolution of the Singapore Chinese Middle School Students' Union and the army conscription of young men. Such political challenges drove the government to curb the influence of Chineselanguage schools by threatening to close down the schools or arresting student leaders. Describing the students involved in protests as "idealists" but "manipulated" by the Communists within the student movements, Liu and Wong (2004) noted that the student leaders "were either detained or left school and were thus deprived of an active platform". Over time, Chinese education became associated with communism and the PAP which assumed leadership "sought to distinguish itself as 'non-communist' and as the vanguard of a new 'multiracial' nationalism" (Kwok \& Chia, 2012, p.234). A leader which emerged from the communist segment of the polity was Lim Chin Siong, a union leader who held a strong appeal to the Chinese community who later became the SecretaryGeneral of Barisan Socialis, an opposition party which was formed by left-wing members of the PAP. According to Tan (2001) and Harper (2001), Lim and his allies were not communists; their aims were to oppose the British colonial rule through non-violent means and unify people through promoting multi-culturalism. However, as Harper (2001) argued, "the rewriting of national histories remains a fraught process. Lim Chin Siong's death in 1996 occurred at a time when 
'National Education' initiatives were being formulated that entrenched the 'Singapore Story' in school curricula" (p.5).

The stigmatization of Chinese education as communism is but one facet of the tenuous relationship between the State and the Chinese-educated community in the history of Singapore; it is also a history of the State disciplining the Chinese-language press, intellectuals and arts practitioners for wading into the sensitive areas of race, language, religion and politics. Chinese newspapers such as Nanyang Siang Pau and Sin Chew Jit Poh were set up in the 1920s and "reflected the political upheavals in China" with Singapore being "a safe haven" from which overseas Chinese movements were founded to support those involved in "the violently polarized politics of the motherland" (George, 2012, p.120). In 1957, four reporters and the publisher of Sin Chew Jit Poh were arrested during an anti-communist dragnet. In 1971, Nanyang Siang Pau criticized the government of destroying the Chinese language and culture, and advocated for Mandarin to be the official langauge of administration, law courts and official publications. The then Prime Minister Lee Kuan Yew accused the paper of "stoking chauvinism", culminating in the arrest of its four executives and the eventual revoke of its publishing permit (George, 2012, p.122). In 1982, Nanyang Siang Pau and Sin Chew Jit Poh merged and were reorganized into Lianhe Zaobao (morning edition) and Lianhe Wanbao (evening edition) a year later.

The social and political consciousness that permeated the Chinese schools and press was also present in the Chinese theatre arena, with socio-political performances attracting "busloads of students and workers to watch" (Chan, 2010, p.29). An influential figure in Singapore's Chinese theatre was - and still is - the late doyen Kuo Pao Kun. For him and his performing school's members, inspiration came from working in the rice fields, plantations and fishing farms - places that were increasingly acquired for industrialization and causing resentment among the farmers. In 1976, under the Internal Security Act, Kuo was detained without trial for leftwing politics and had his citizenship revoked until 1992.

One of the biggest setbacks - and a continuous source of grievance - for the Chinese-educated in Singapore has to be the closure of Nanyang University or Nantah. Founded in 1953 and regarded as "the jewel of Chinese education in Southeast Asia but a bastion of resistance to the government in the field of education" (Tan, 2002, p.114), the university accepted English as a language of instruction in 1975 before being merged with the University of Singapore in 1980 to form the National University of Singapore, despite opposition from the Nantah alumni. Given the history of clampdowns and closures, it is perhaps unsurprisingly that the outcome was that of "a longstanding rift between the PAP government and the Chinese-educated" and for the latter to "harbour latent fears of political and cultural marginalization" (Tan, 2009, p.331-332).

However, the rise of China and the accompanying economic advantage of mastering the Chinese language prompted the Singapore government to launch the 'Speak Mandarin Campaign' in 1979. Some scholars associated the campaign with promoting Chinese at the expense of the Chinese dialects with Mandarin being depicted as a common language unifying the different Chinese dialect groups (Tan, 2012). The success of the 'Speak Mandarin Campaign' could be partially gauged from the declining numbers of ethnic Chinese in Singapore speaking their dialects 
- 19.2\% in 2010 as compared to 30.7\% in 2000 (Census of Population 2010, Department of Statistics Singapore). The economic justification for learning the English language was internalised by many Chinese parents and this contributed to dwindling enrolment numbers in Chinese language schools. Cognizant of this development and Chinese being the largest ethnic community in Singapore, scrutiny of the implications of Chinese blogs is thus timely.

\section{Research Aims and Methodology}

Although existing studies on blogs in Singapore have established the political implications of blogging, they focus on English sites (for example, George, 2006; Skoric \& Ng, 2009; Soon, 2013; Soon \& Cho, 2014; Soon \& Kluver, 2014). The body of work on blogging in vernacular languages is limited both in quantity and scope. Any work done in this domain was related to the use of such blogs for teaching and learning and by diasporas residing in Singapore (e.g., Chinese immigrants from China) to connect with their fellow countrymen (He, 2007; Huang, 2009; Jyh, 2009; Sim, 2008; Tan \& Tan, 2010; Ubaidullah, Mahadi \& Lee, 2013).

In Singapore, $87 \%$ of households have Internet access and the mobile penetration rate is at $150 \%$ (Information Development Authority of Singapore, Facts and Figures, 2014). Despite increasing IT penetration and increasing trends of new media use for civic engagement, little is known about if and how the Chinese community use blogs. Thus this study seeks to examine the Chinese blogosphere in Singapore and its political significance, if any. Specifically, we seek to determine characteristics such as the size of the Chinese blogosphere, the level of activity of these blogs, who the bloggers were (to as far as can be determined from blog content) and the issues they blogged about. We also examine their blogging practices which shed light on their affiliations (or lack thereof) and motivations for blogging in Chinese (as opposed to English, the lingua franca). In so doing, we examine the presence and degree of politicization of Chinese blogs, specifically if and how they contribute to public discourse.

\subsection{Sample}

The sample for this study was collected from November 2013 to January 2014 in two stages keyword searches via commercial search engines and snowballing the sample. Keyword searches were conducted using Google Chinese, Google English and Yahoo! to locate seed blogs. No major events of political, economic or social significance took place during this period, hence the discourse found on the blogs reflected the 'everyday' activities and interests of the bloggers. Subsequently, we "snowballed" the population by tracing hyperlinks from each seed blog to other blogs. We repeated the snowballing process till we reached sample saturation (i.e., when we stopped finding new blogs). Only active blogs - those with at least one blog update made within the last year prior to data collection - were included. As we were interested in studying blogs related to Singapore (as people of Chinese descent living in other parts of the world may also blog in the Chinese language), we used this criteria to identify relevant blogs: (i) At least $50 \%$ of the blog content is written in the Chinese language and (ii) the blogs must be related to Singapore (i.e., they are either started by Singaporeans, Singapore-based bloggers, or bloggers located out of 
Singapore blogging on Singapore-related issues). Where the nationality or residency of bloggers cannot be determined, at least $50 \%$ of the blog content must be related to Singapore.

\subsection{Content Analysis}

To determine the features of the Chinese blogosphere, we analyzed the following categories. Two coders were involved in coding and the Cohen's kappa score was 0.80 .

- Size and characteristics of the Chinese blogosphere - We determined the size of the Chinese blogosphere through the two-stage process described earlier and used Herring, Scheidt, Bonus and Wright's (2004) coding scheme to identify the recency of update and age of blog.

- Who Chinese bloggers were - We determined their age, gender and professions by studying their profile pages or drawing inferences from blog content when demographic information was not explicitly stated (we omitted blogs where both methods were not feasible).

- Blog type - We used categories (personal-type blogs, knowledge blogs or k-logs, filter blogs and mixed-type blogs) developed by Herring et al. and added aggregators to the list.

- Issues blogged about - We adopted categories of topics ("politics", "social issues" and sports" etc.) from existing studies (Trammell, Tarkowski, Hofmokl \& Sapp, 2006; Yu, 2007). To determine the topics bloggers wrote about, we studied the blog posts, used the frequency count method and recorded all the topics a blogger blogged about ${ }^{4}$.

- Bloggers' affiliations - We analysed the home page of each blog for the presence of badges and their hyperlinks to other sites.

- Presence of advertisements - We analysed the home page of each blog for the presence of advertisements.

\subsection{Survey}

An online survey was also conducted in February and March 2014 to collect information on bloggers' blogging experiences, motivations and reasons for blogging in Chinese. Invitations were sent via email to bloggers who published their email contacts on their blogs. Where email contacts were not available, we left invitations in the comment section on their blogs. Invitations were sent to all bloggers identified through the sampling method described earlier. The survey included questions on bloggers' demographics, their blogging practices, their reasons for blogging and for doing so in Chinese. In this paper, we focused on the findings for bloggers' motivations to blog in Chinese. The respondents were asked the question "Why do you blog in the dominant language?". The respondents were asked to rate various reasons for blogging in the dominant language on a scale of 1 to 5 ( 1 being "strongly disagree"; 2 being "disagree"; 3 being "neither agree nor disagree"; 4 being "agree"; and 5 being "strongly agree"). Twenty six bloggers (13\% of the total number of bloggers) participated in the online survey.

${ }^{4}$ A blog would be counted multiple times if the blogger writes on more than one type of issue. 


\section{Findings and Discussion}

\subsection{Characteristics of the Chinese Blogosphere}

Through keyword searches and seven rounds of snowballing, we found a total of 201 Chinese blogs which met our criteria. The mean age of the 201 blogs was five years $-27 \%$ of the blogs have been active for four to six years, while $33 \%$ of the blogs were six to 10 years old (see Figure 1). Chinese blogs were of medium activity with the majority $(48 \%)$ being updated within the last three months.

Figure 1: Age of Blogs

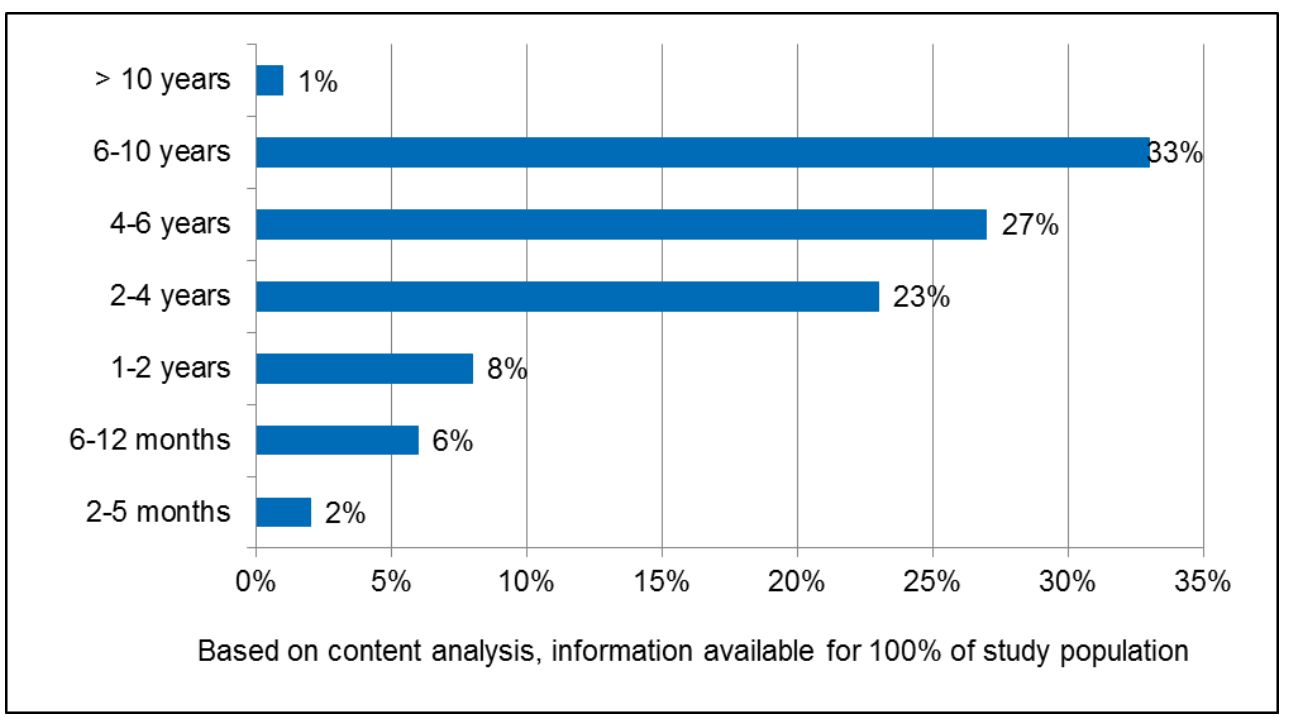

\subsection{A Peek into Who Chinese Bloggers Are}

Based on content analysis, we were able to infer the age of the bloggers for 49 of the 201 blogs. Of this group, $43 \%$ were in their 20 s and $47 \%$ were in their 40 s to 50 s. Out of the 137 blogs for which researchers were able to determine the bloggers' gender, $58 \%$ were female and $42 \%$ were male. The Chinese blogosphere comprised mainly Singaporean Chinese and a small group of Malaysian Chinese. About $2 \%$ of the blogs were started by Chinese immigrants from China. Information on bloggers' professions was either self-declared by the bloggers or inferred from their blog posts.

The three largest occupational groups were the media sector (e.g., journalists and radio deejays at $25 \%$ ), creative industries (such as graphic designers and illustrators at 20\%), and education (consisting of academics, researchers and teachers at 14\%). See Figure 2. The professional profiles of the bloggers indicated that the Chinese language formed an integral part of their professional and personal lives. Among the bloggers were radio presenters, journalists from newspapers, magazines and television, undergraduates majoring in Chinese Studies (a discipline offered in the National University of Singapore and Nanyang Technological University), teachers and academics doing research on the Chinese language, literature and culture. 
Figure 2: Professions of Chinese Bloggers

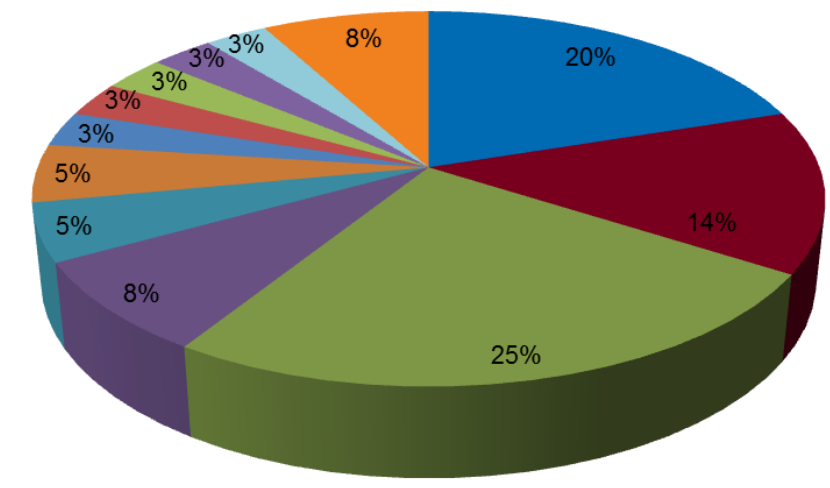

- Creative industries

- Education

- Media

- Engineering

- Finance

- Entrepreneur

- Non-profit

- Advertising

- Architecture

- Pharmaceuticals

- Psychology

- Homemaker

Based on content analysis, information available for $20 \%(n=40)$ of study population

\subsection{Popular Blog Types}

Chinese blogs consisted of personal-type blogs, k-logs, aggregators and mixed-type blogs. Figure 2 shows the breakdown of the types of blogs. Filter blogs where bloggers developed narratives or discussions based on commentaries of selected hyperlinks to other sites did not exist in the Chinese blogosphere.

Figure 3: Blog Types

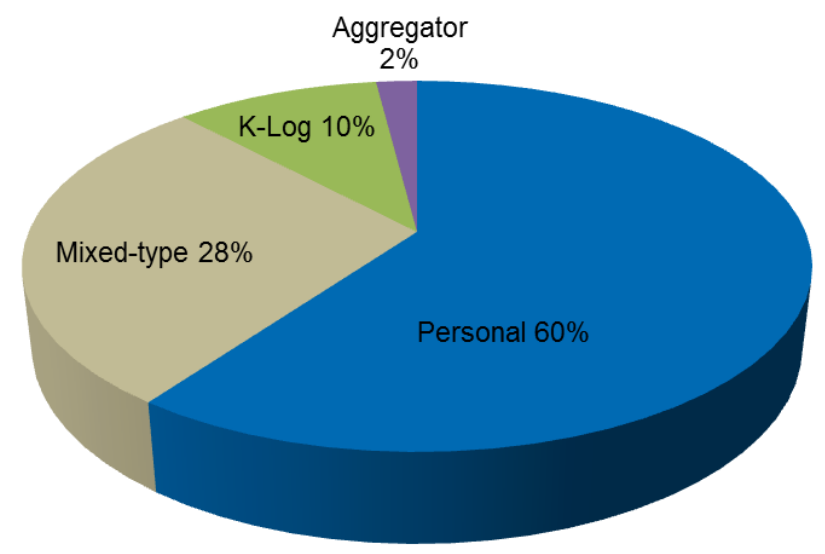

Based on content analysis, information available for $100 \%$ of study population

The majority, $60 \%$, were personal-type blogs where the blogs served as bloggers' online diaries. In a personal-type blog, the blogger narrates and reflects on his or her personal life experiences related to work, school and family life. One such example is Fungtasia (http://blog.omy.sg/fungtasia/). A k-log serves as a knowledge management system or 
repository where the information or references blogged about are specific to one domain. $10 \%$ of the Chinese blogs belonged to this category. Some examples of Chinese k-logs included blogs on food, Chinese history and the historic Bukit Brown cemetery (e.g.; http://bukitbrowntomb.blogspot.sg/). An aggregator collates information from multiple online sources. In most cases, individuals operating aggregators did not express their opinions on the blogs. About $2 \%$ of Chinese blogs were aggregators, collecting news articles on politics, the economy and culture in Singapore (e.g. http:/ / xinguozhi.wordpress.com/). The remaining 28\% of the blogs were mixed-type blogs. Some of these mixed-type blogs were personal-type blogs and klogs that incorporated the feature of filter blogs, with commentaries based in hyperlinks to news websites and YouTube videos (e.g. http://blog.omy.sg/annalim/).

\subsection{Issues Blogged about}

The most common topic blogged about is "personal experiences", with about $75 \%$ of Chinese blogs containing entries on bloggers' personal experiences such as their travels, dining experiences and time spent with friends and family (see Figure 3). Bloggers' friends and family members (49\% of the blogs) also featured prominently in their blog entries, evident in the blog posts and photographs taken of their family outings or at gatherings with former classmates.

Figure 4: Issues Blogged about by Number of Blogs

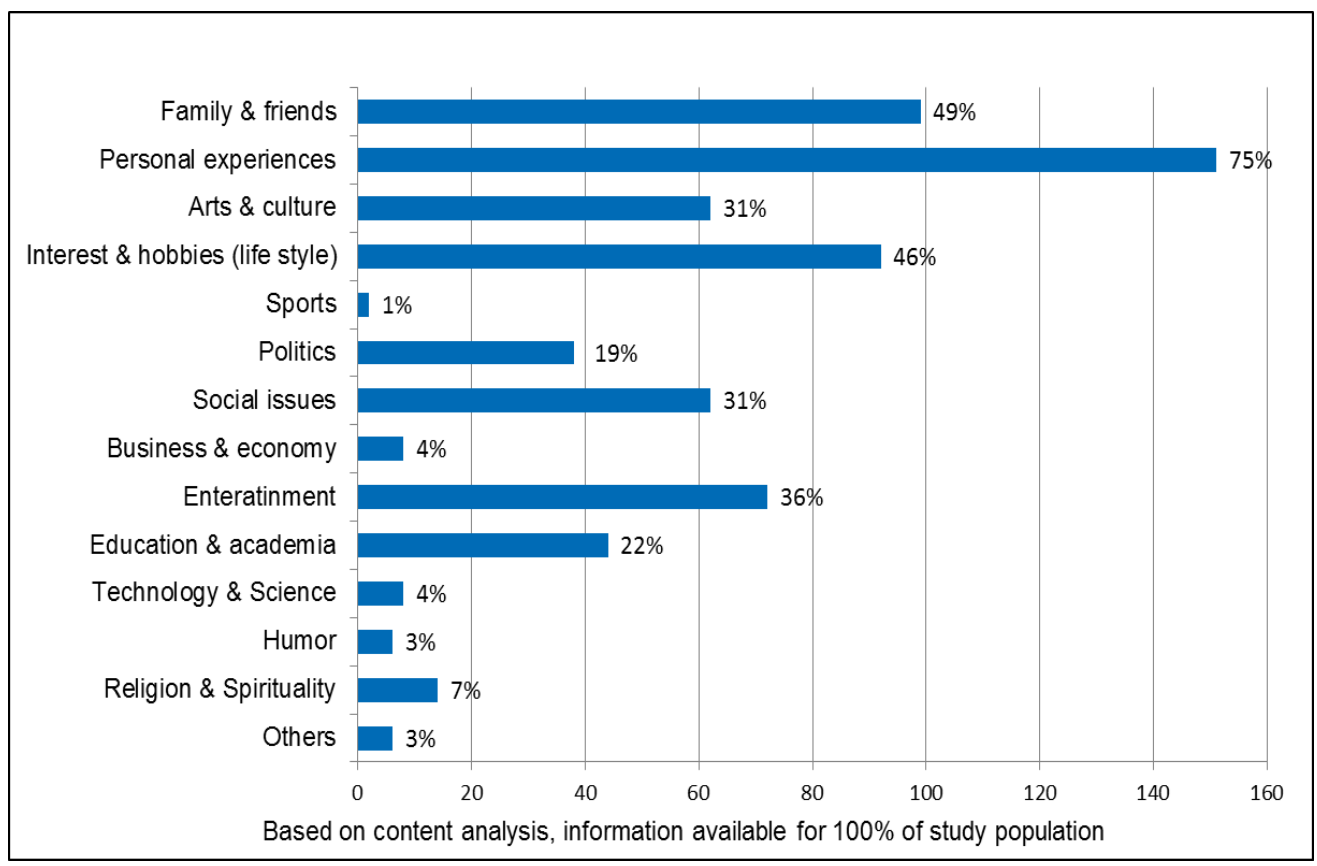

The third most common topic was "interests and hobbies" (46\% of the blogs) and some examples of the interests and hobbies included food, photography and collecting phone cards. Another commonly blogged topic is "entertainment", with $36 \%$ of the blogs discussing and reviewing television programmes, films and music videos. 
Two categories of topics merit some discussion here. About $31 \%$ of Chinese blogs contained posts related to the arts and culture. This category included topics on the Chinese language, culture and traditions. A dominant theme of discussion was the declining standards of Chinese as a mother tongue language in Singapore with some bloggers cautioning against implementing any policy of making it easier to learn the language in schools as they fear it might lower its standard (e.g., http://blog.omy.sg/shehu/ and http://blog.omy.sg/ahgongahmagoodoldtimes/).

A small group of bloggers $(19 \%)$ provided occasional commentaries on certain policies or political issues, ranging from media regulation to transportation policies. For example, some bloggers questioned the rationale behind the move to license online news websites while others attributed declining traffic conditions to poor planning. Only about $4 \%$ can be called socio-political blogs - blogs that focus mainly on politics and policies related to Singapore. The study also established that "politics" as blogged about in the local Chinese blogosphere were not limited to Singapore politics. Since the study includes foreigners working or studying in Singapore, there have been instances of Malaysians blogging about political campaigns and elections in their country of origin. However, these Malaysian Chinese bloggers did not write about Singapore politics.

\subsection{Bloggers' Affiliations}

Almost $90 \%$ (179 blogs) of the blogs had badges (defined by Herring et al. as visual representations of a blogger's affiliation with a group, association or cause). The most common badges were those related to blogging awards such as the Singapore Blog Awards - bloggers who featured these badges were either nominees or recipients of such awards. Other examples of badges included those of the Liverpool Football Club and Bento Bloggers Network. While there was one blog that contained a badge featuring the ribbon symbol of the HIV/AIDS awareness campaign, there was no indication of the rest of the Chinese bloggers' affiliations or support for well-known campaigns and movements such as "Repeal 377A"5, Pink Dot Sg6 or Save Bukit Brown7. This contrasts sharply with the high prominence at which the same issues were featured on English blogs (Soon, 2013; Soon \& Cho, 2014; Soon \& Kluver, 2014).

We also analysed bloggers' hyperlinking patterns to ascertain the types of networks bloggers build in the cyberspace. See Figure 4.

${ }^{5} \mathrm{~A}$ campaign to repeal Section 377A of the Penal Code which criminalizes sex between two men, with provisions for a jail sentence for up to two years.

${ }^{6}$ An annual campaign that advocates the freedom to love for the LGBT community and culminates in a picnic at the Speakers' Corner.

${ }^{7}$ A joint campaign by various groups to protest against state plans to construct a highway through part of Bukit Brown, Singapore's oldest cemetery. 
Figure 5: Sites Linked from Chinese Blogs

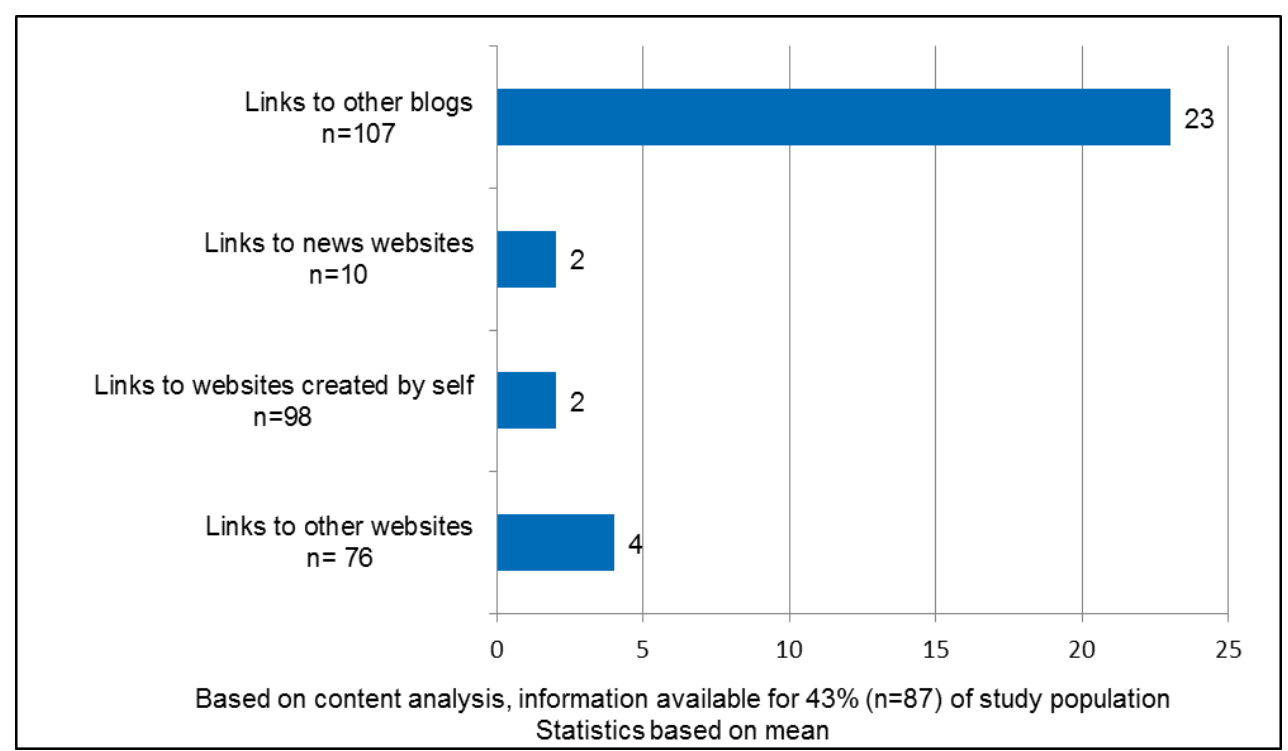

Over half of the Chinese blogs were linked to other blogs on their blog rolls, with an average of 23 links to other blogs. On the whole, bloggers were more likely to link to other blogs if the linked blogs were also written in Chinese or if they covered similar topics. About $49 \%$ (98 blogs) of the blogs had links to websites and blogs created by the same blog owners. Some of these linked blogs were created earlier by the owner and have since been discontinued. $38 \%$ of the blogs (76 blogs) were also linked to other websites. Similarity in content or focus could be a possible reason for these linkages. For example, a blog with photographs documenting a blogger's travels had links to a website that provided tips on photography. Similarly, a blog covering mostly arts and culturerelated topics had links to the websites of theatre companies in Singapore.

The majority of the blogs (68\%) carried commercial advertisement banners, such as those for lifestyle, telecommunications, educational, financial, health and beauty products (see Figure 5). Some of these advertising banners featured household brands like M1 (a telecommunications service provider), United Overseas Bank and Osim (massage equipment). Besides advertising, sponsorship provides bloggers with another source of income. Travelgraphy (www.travelgraphy.wordpress.com) was a bilingual travel blog written in Chinese and English. Logos of tourist associations, budget airlines and hotels that likely sponsored the blogger's overseas trips were displayed on the "Collaborations" page of the blog. 
Figure 5: Number of Chinese Blogs with Advertisements

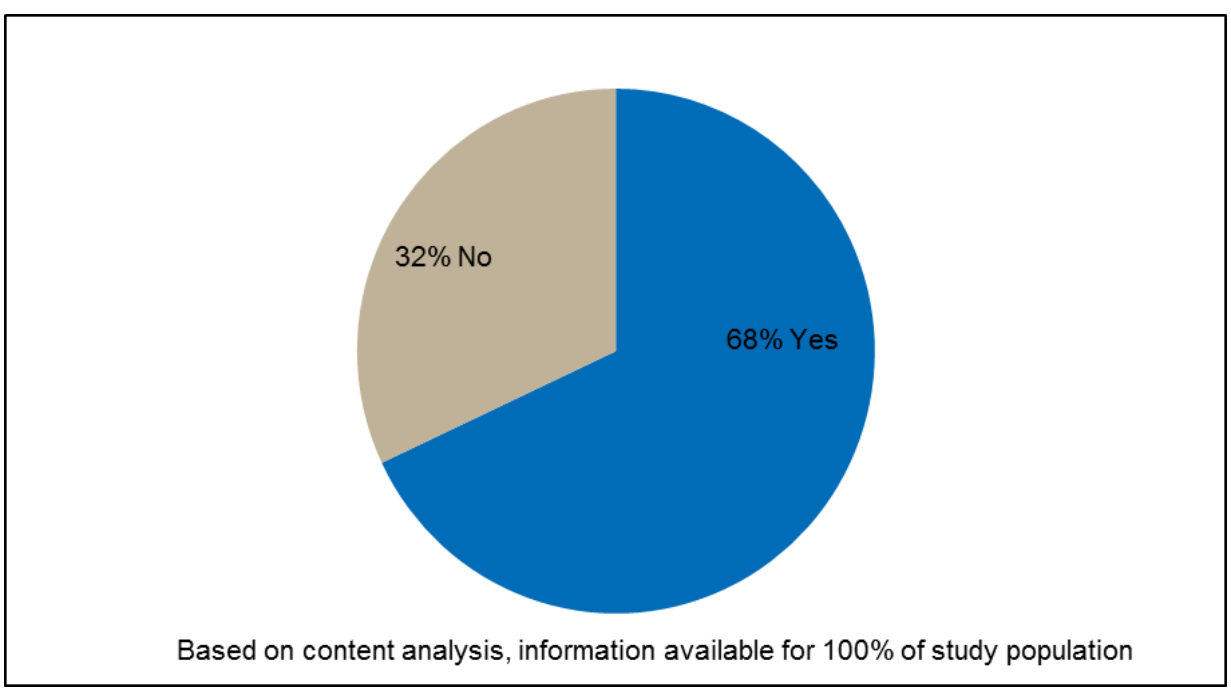

\subsection{Motivations for Blogging in Chinese}

From 26 responses, the survey shed some interesting insights on why bloggers blogged in Chinese. The highest number (92\%) cited that they were most competent in Chinese and another $88 \%$ felt that they expressed themselves most effectively in that language. A desire to maintain the use of the language was expressed by $77 \%$ who said that "they would like to keep in touch with the language"; 69\% who would like to "improve their language skills"; and 58\% who wanted to "preserve the use of the language". Language seems to be an integral part of their personal identities with almost half $(46 \%)$ of the respondents saying that using the language helped them to express their ethnic identity.

Figure 6: Motivations for Blogging in Chinese

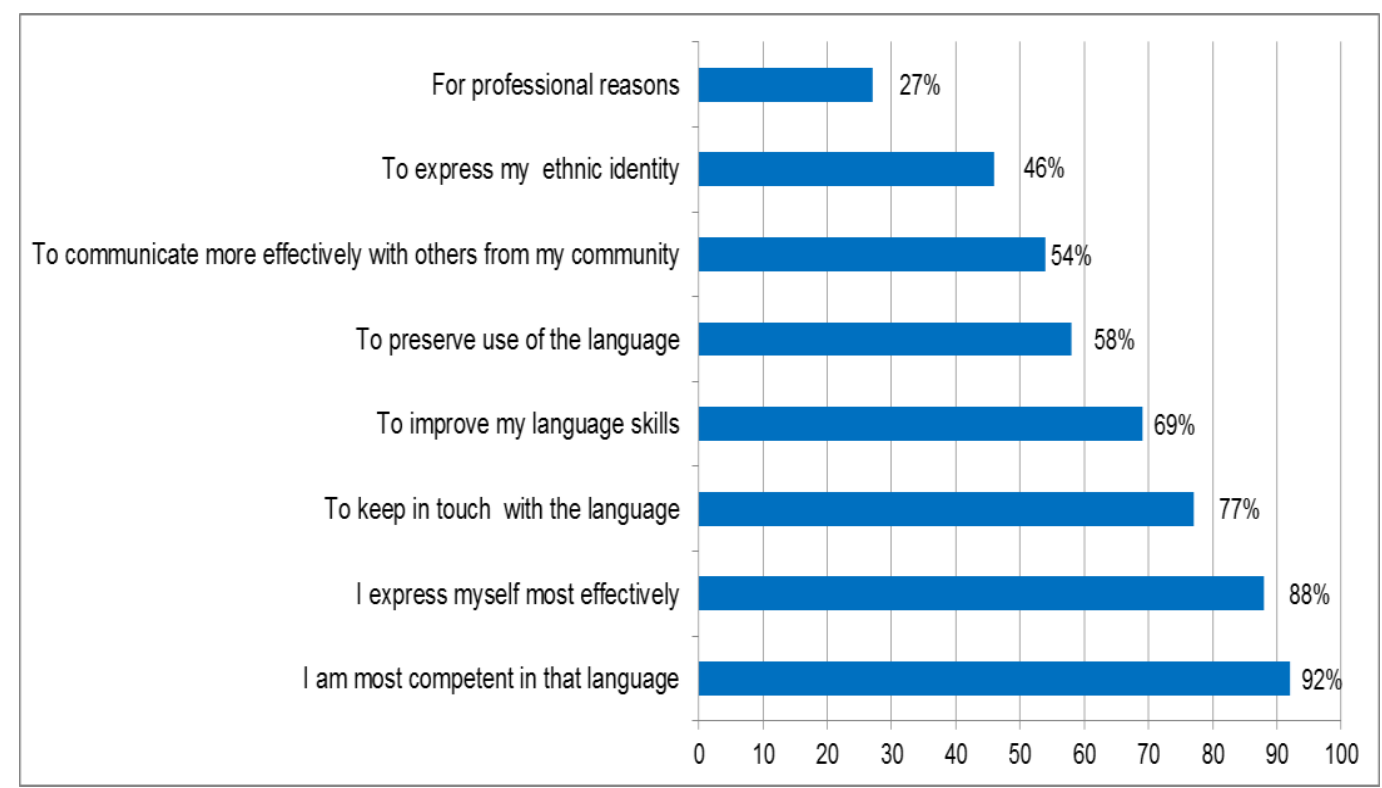




\subsection{Chinese Language Used in Standard Form}

Most of the blogs were written in standard Chinese (using the Simplified Chinese script) as taught in schools and used in the Chinese language media in Singapore. There was little mixing of languages in the writing. Different languages were used for different blog entries in bilingual blogs where bloggers wrote in both Chinese and English, i.e., a blog entry written entirely in English and another blog entry written completely in Chinese. English words were used to reference proper nouns such as names of specific places or particular persons (e.g., Lee Kuan Yew's book One Man's View of the World, "PSI" for the Pollution Standard Index and "Marina Bay Sands").The bloggers also demonstrated a good repertoire of language usage. Some wrote in simple Chinese while others demonstrated an extensive vocabulary through the use of idiomatic language and Chinese proverbs to express their ideas and opinions. "Quah Bak Lim” (http://kuabaklim. blogspot.sg/) was one such example.

\subsection{Preservation of Chinese Language and Culture}

There is an indication that Chinese language bloggers' concerns over the declining standards of the Chinese language and the disappearance of Chinese dialects serve as an impetus for them to write in Mandarin so as to preserve the language. For example, "She Hu" (http://blog.omy.sg/shehu/) was set up by a group of Singaporeans - some based in the United States - who were passionate about the Chinese language. Their blog posts consisted of Chinese riddles, reflecting their espoused aim of promoting the learning of Chinese among the younger generation in a fun manner. Similarly, “Grandma Grandpa Story” (http://blog.omy.sg/ ahgongahmagoodoldtimes/) was the brainchild of a group of students from a tertiary institution (Ngee Ann Polytechnic) and was dedicated to raising awareness of the Chinese storytelling tradition among the younger generation. These blogs focused on the younger generation as their key audience, suggesting that the bloggers saw the importance of transmitting the Chinese language and culture to future generations.

For the majority of bloggers whose blogs were personal-type blogs and not dedicated solely to the preservation of the Chinese language and culture, their writing on these issues was sporadic and largely shaped by external events happening in Singapore. For instance, a blogger who was also a local media personality wrote that the onus was on parents and not the government to teach Chinese dialects to the young. His blog post responded to a comment made by Education Minister Heng Swee Keat (http://blog.omy.sg/dannyyeo/page/22). Likewise, the discussion on Chinese dialects resurfaced with the screening of the local film "The Girl in Pinafore" which featured a song that contains some lyrics in Chinese dialects and was previously banned on local radio (http://lanyu.wordpress.com/2014/02/).

\subsection{Mainstream Chinese Media as Reference, not Adversary}

Some Chinese blogs contained links to Chinese news websites such as Lianhe Zaobao and MyPaper (two newspaper dailies). Some blogs also posted scanned images of newspaper articles or included hyperlinks to news websites and structured commentaries around the topics featured 
in mainstream media. The mainstream media were used as a source of information and reference in Chinese blogs. This is different from English socio-political blogs which used mainstream media as an object of critique, pointing out limitations and perceived biases in media coverage of contentious political and social issues (Hussein, 2008; Soon \& Kluver, 2014).

An example of such a blog is Sg Facts Blog (http://sgfactblog.wordpress.com/), a 15-year-old blog which was among the few aggregators in the Chinese blogosphere. The blogger aggregated reports and articles from mainstream Chinese media and archived them according to categories such as "Population", "Housing", "Education" and "New Media".

That mainstream media was not an object of critique could be attributed to the intersection of mainstream media and parts of the Chinese blogosphere. As mentioned earlier, the media sector, creative industries and education sector constituted the biggest occupational groups for bloggers whose occupations could be determined through the content analysis. It has been observed that individuals who work as journalists and editors in mainstream media also reproduced their articles on their own personal blogs. Examples include the blogs run by a Lianhe Zaobao reporter (http://blog.omy.sg/sihan/) and an editor of a Chinese-language female magazine (http://tonfucius.blogspot.sg/). Other bloggers who worked in fields like academia and graphic design also penned articles and commentaries for the mainstream media on a freelance basis (for example: http://lanyu.wordpress.com/ and http://solidair23.blogspot.sg/). Their articles were similarly reproduced on their blogs.

\subsection{A-Political Nature of Chinese Blogs}

As established earlier, less than $10 \%$ could be considered as socio-political blogs. Examples of such blogs included Renmin Luntan (http://wangruirong.wordpress.com/), Piji Tailai (http://pijitailai.blogspot.sg/) and Baima Feima (http://yennyhanaike.wordpress.com/). The discussion found in these blogs focused on political issues and policy limitations, and rarely on lifestyle topics such as fashion, food and entertainment that were commonly associated with personal-type blogs. A discernible difference was observed in the approach these bloggers adopted when writing about political issues as compared to English bloggers. Earlier studies have established that English bloggers tend to be critical of the government and its policies, with the majority being very acerbic in their criticisms (Soon \& Kluver, 2014; Soon \& Tan, 2013). The few Chinese socio-political blogs adopted a more balanced and moderate approach, a stark contrast from the confrontational discourse present in English blogs.

This was evident in how they acknowledged different perspectives when discussing different policies. Two such examples were Renmin Luntan (http://wangruirong.wordpress.com/) and Unlimited Blue Skies (http://kokchwan.blogspot.sg/). When the blogger of Unlimited Blue Skies commented on the Punggol by-election, the blogger discussed the implications of Workers' Party's win in a Group Representative Constituency and what their victory meant for local politics. However, the blogger also cautioned that only time would tell if having more opposition in the parliament would make a difference. There was also a stark absence of name-calling and vitriolic speech. Their apolitical nature was evident in the absence of endorsement (through badges) of 
popular campaigns organized by the civil society, unlike in the English blogosphere (as presented in Section 4.5).

The socio-political blogs were characterized by a high degree of anonymity. With the exception of a blog (http://gohmengseng.blogspot.sg/) which was maintained by an opposition politician, the bloggers behind the other socio-political blogs kept their identities confidential. Another blogger (http:/ / kokchwan.blogspot.sg/) used a pseudonym for identification. For blogs that had a profile page, there was little information to be gleaned beyond those on gender, location and hobbies. In addition, none of these socio-political blogs had listed an e-mail address for readers to contact the bloggers although several allowed readers to register as subscribers by submitting their e-mail addresses. That these socio-political blogs function in anonymity and relative isolation begs further investigation, as to whether this represents a form of modus operandi designed to reduce the risks of repercussions of commenting on political issues.

For the remaining 90\% that were not socio-political blogs, the majority of them were personaltype blogs and k-logs that focused on personal experiences, interests and hobbies. A small number of these bloggers blogged on political issues (e.g., language policies) and on an ad hoc basis. They occasionally adopted a political stance when raising their objections to newly implemented policies. Examples of such narratives of resistance include voicing one's doubts about the Nominated Member of Parliament scheme and criticizing the logic behind subjecting online news websites to licensing. Their commentaries on policies and socio-political issues could be described as passive, as their decisions to blog on such topics were dependent on the occurrence of political "events" such as the holding of general elections (http://blog.omy.sg/mingde/2011/05/25/) or the perceived failings of policies. For example, the unreliability of public bus services prompted a blogger to question the effectiveness of transportation policies (https://limhe.wordpress.com/2014/01/). Moreover, contrarian viewpoints on politics and policies were rare and not sustained; while readers occasionally left comments on the blogs in response to the bloggers' posts, the comments seldom translated into a prolonged dialogue, let alone action. The bloggers also did not use their posts as a platform to mobilize support or promote activism to engender social or political change.

The largely a-political character of the Chinese blogosphere could also be discerned from the blogosphere's limited networks to politicized online spaces. Only about 4\% of the 201 Chinese blogs contained links to socio-political news websites such as The Online Citizen (www.theonlinecitizen.com) and Singapore Rebel (www.singaporerebel.blogspot.sg/), as well as Singapore Daily (http://singaporedaily.net), an aggregator of alternative blogs and websites in the English language. Other links were to blogs run by well-known government critics Alex Au (http://yawningbread.wordpress.com/), Andrew Loh (http://andrewlohhp.wordpress.com/) and Roy Ngerng (http:/ / myrighttolove.com/). 


\section{Conclusion}

We set out to ascertain the characteristics of the Chinese blogosphere in Singapore and explore the extent of politicization among Chinese blogs. While there are occasional posts which point to Chinese bloggers' interest in social issues such as the plight of Singapore's elderly, the declining standards of the Chinese language and Singapore's immigration policies, our study elucidates that Chinese bloggers generally blog alone. By this we mean that blogging to Chinese bloggers functions more as personal activity as opposed to a community-related one. Most of the content on their blogs were about their personal experiences and their blogs were conduits for them to express their personal views and to showcase their pastimes and interests (e.g., food, travel, photography and music). Furthermore, with the exception of linking to other blogs and websites dealing with similar topics, there is little or no evidence of communication among the blogs. Most Chinese bloggers did not hyperlink to, cite or quote other bloggers in the articles (posts) on their blogs. Our analysis found that Chinese bloggers did not use their blogs to galvanize support for a specific issue. There was also an absence of an articulation of a "we" or collective.

One reason for the blogs' apolitical nature might be the "chilling effect" of earlier clampdowns on Chinese student movements, Chinese press, arts practitioners and intellectuals. The "public voicing of grievances within a discourse of race" also led to one being labelled as a "racial chauvinist" (Chua, p.75). The most well-known case of "Chinese chauvinism" arguably took during the General Elections in 1997 when opposition politician Tang Liang Hong "was accused of arguing that there were too many Christians and English-educated people in the Cabinet and civil service, and complaining that Chinese-educated Singaporeans were carrying the sedan chair for others when they should instead have been sitting on it". Labels like "extremist", "anti-English educated" and "dangerous Chinese chauvinist" were used by the PAP on Tang (Huang, 2009, p. 339). Such labelling could have contributed another layer to the chilling effect, further deterring people from speaking their minds. Even as recently as July 2014, an editorial in Lianhe Zaobao pointing to the chasm between the dialect-speaking older generation and the English-speaking younger generation due to the country's Speak Mandarin Campaign and bilingual policy invited a rebuttal from the Prime Minister's Office. It described the editorial as extreme, not objective and "does not do justice to the government" (Ong, 2014).

The strong presence of advertising in the Chinese blogosphere mirrors the "intensified commercialization" of the Internet (Dahlgren, 2005, p. 151) and this finding has implications on this study's aim of assessing the extent Chinese blogs were politicized. Scholars such as Papacharissi (2002) have noted that the Internet is a product of capitalism and technologies can be commodified and transformed by capitalist patterns of production into "commercially oriented media that have little to do with promoting social welfare" (p. 20). Advertising as an instrument of self-censorship and censorship has been well-documented (Craig, 2004) and further research is warranted to investigate if the Chinese blogosphere's advertising does have an impact on its extent of politicization, such as whether bloggers avoid writing about sensitive topics such as politics out of concern of alienating advertisers. 
An interesting comparison can be made between Chinese blogs in Singapore and from other countries where the Chinese language is used in blogging. While some studies have considered the use of blogs for non-political reasons (e.g., Law \& Cheung, 2010; Tse \& Zhang, 2012; Yang, 2007), several others examined the political significance of blogs in China. On the level of politicizing of blogs in China, Zhou (2009) found Chinese bloggers to be actively discussing politically sensitive issues, to the point of criticizing the Chinese government. In their study of blog use by gays and lesbians in China, Kang and Yang (2009) posited that "the emergence of blog technology has generated a rhetorical borderland that allows homosexual people in China to circumvent the oppression of heterosexual hegemony" (p.25). However, such optimism was tempered by the Chinese government's capacity and competency in reining in online discourse and the adherence of a large part of the population to official versions of Chinese history and current affairs (MacKinnon, 2008). It is evident that Chinese blogs in Singapore do not play as a large a role in contributing to public discourse compared to Chinese blogs in China. The stigma attached to Chinese activism could still be at work, signalling that blog use reflects the nuances present in a society's political and historical context. Earlier, a China-born blogger interviewed by the mainstream press had alluded to being more "sensitive to others" when blogging after migrating to Singapore due to the country's history and multi-culturalism (Zhao, 2010).

There are several limitations to this study. First, although keyword searches and the snowballing process have yielded as exhaustive as possible a sample for the Chinese blogosphere, there is a possibility that some blogs may have been excluded. For example, blogs which do not provide any information on the bloggers' locality and nationality, and do not have any content related to Singapore may have been excluded even though they may be started by Singaporeans or Singapore residents. Second, some bloggers might have moved to social media such as Facebook and we would not have captured discourse on those platforms. The content analysis method limits our analysis of the reasons behind bloggers' blogging patterns. Although shedding some important insights on why Chinese bloggers blogged in the vernacular language, the response of the survey was low and hence the finding may not be representative of the Chinese blogosphere. Given the low participation rate for the online survey, it would be difficult to ascertain if the survey responses are representative of the Chinese blogosphere. Nevertheless, it appears that language competency (92\%) and a desire to keep in touch with the Chinese language (77\%) were the bloggers' primary motivations for blogging in Chinese. This survey finding corroborated findings from the content analysis on popular issues discussed.

Despite the limitations, this study is a first in providing an empirical snapshot of Chinese blogs in their current form. It serves as a record for purposes of comparison with future stages of nonEnglish blogs' evolution and provides a starting point for further research on their contribution. In summary, our study sheds light on an unknown population of the online space which has so far been omitted in public discourse. Our findings also caution against transplanting common assumptions and findings pertaining to blogs in a particular language to those written in another language. Differences in terms of approach and level of politicization are observed even among Singaporeans blogging in different languages (e.g., English versus Chinese), a clear indication that 
nuances of online discourse must be considered along political and cultural forces that shape institutional developments.

\section{References}

Adams, J., \& Roscigno, V. J. (2005). White supremacists, oppositional culture and the World Wide Web. Social Forces, 84(2), 759-778.

Amir-Ebrahimi, M. (2008). Transgression in narration: The lives of Iranian women in cyberspace. Journal of Middle East Women's Studies, 4(3), 89-118.

Ayers, M. D. (2003). Comparing collective identity in online and offline feminist activists. In M. McCaughey, \& M. D. Ayers (Eds.), Cyberactivism: Online activism in theory and practice (pp.145-164). New York, NY: Routledge.

Bosch, T. (2010). Digital journalism and online public spheres in South Africa. Communicatio, 36(2), 265-275.

Buechler, S. M. (1993). Beyond resource mobilization? Emerging trends in social movement theory. Sociological Quarterly, 34(2), 217-235.

Chan, M. (2010). Kuo Pao Kun: The Spirit of the Eagle. Contemporary Theatre Review, 13(3), 26-32.

Chua, B. H. (1985). Pragmatism of the People's Action Party government in Singapore. Southeast Asian Journal of Social Science, 13(2), 29-46.

Chua, B. H. (2003). Multiculturalism in Singapore: An instrument of social control. Race \& Class, 44(3), 58-77.

Craig, R. L. (2004). Advertising, Democracy and Censorship. Javnost - The Public: Journal of the European Institute for Communication and Culture, 11(2), 49-64.

Dahlgren, P. (2005). The internet, public spheres, and public communication: Dispersion and deliberation. Political Communication, 22, 147-162.

Department of Statistics (2010). Census of population 2010. Statistical release: Demographic characteristics, education, language and religion. Available at http://www.singstat.gov.sg/publications/publications_and_papers/cop2010/census_2010_release1/c op2010sr1.pdf

Diani, M. (2000). Social movement networks virtual and real. Information, Communication \& Society, 3(3), 386-401.

Fu, F., Liu, L.H. \& Wang, L. (2008). Empirical analysis of online social networks in the age of Web 2.0. Physica A, 387, 675-684

George, C. (2006). Contentious journalism and the Internet: Towards democratic discourse in Malaysia and Singapore. Singapore: Singapore University Press.

George, C. (2012). Freedom from the Press: Journalism and State Power in Singapore. Singapore: NUS Press.

Gurak, L. J., \& Logie, J. (2003). Internet protests from text to web. In M. McCaughey, \& M. D. Ayers (Eds.), Cyberactivism: Online activism in theory and practice (pp.25-46). New York, NY: Routledge. 
Harper, T.N. (2001). Lim Chin Siong and the "Singapore Story". In Tan J.Q. and Jomo K.S. (Eds.), Comet in our sky (pp.3-55). KL, Malaysia: INSAN.

He, Y. (2007). Exploring the Chinese blogosphere: The motivations of blog authors and readers. Master Thesis, National University of Singapore.

Herring, S. C., Scheidt, L. A., Bonus, S., \& Wright, E. (2004). Bridging the gap: A genre analysis of weblogs. Proceedings of the 37th Annual Hawaii International Conference on System Sciences, Track 4, Vol.4.

Hill, M. \& Lien, K. F. (1995). The politics of nation building and citizenship in Singapore. London \& New York: Routledge.

Ho, K. C., Baber, Z., \& Khondker, H. (2002). 'Sites' of resistance: Alternative web sites and state-society relations. British Journal of Sociology, 53(1), 127-148.

Hong, L. \& Wong, S. K. (2004). Singapore Chinese society in transition: Business, politics and socio-economic change, 1945-1965. New York: Peter Lang Publishing, Inc.

Huang, J. L. (2009). Dilemma and anguish of the Chinese-educated. In Welsh, B., Chin, J., Mahizhnan, A., \& Tan, T. H. Impressions of the Goh Chok Tong Years in Singapore. Singapore: NUS Press-IPS.

Huang, Z. (2009). The Internet world of new Chinese immigrants in Singapore: A study of identity. FinalYear-Project, Nanyang Technological University.

Ibrahim, Y. (2009). Textual and symbolic resistance: Re-mediating politics through the blogosphere in Singapore. In A. Russell, \& N. Echchaibi (Eds.), International blogging (pp.173-198). New York, NY: Peter Lang Publishing.

Information Development Authority of Singapore, 2014. Facts and figures. Retrieved from http://www.ida.gov.sg/Infocomm-Landscape/Facts-and-Figures

Jenkins, H. (2006). Fans, bloggers and gamers: Exploring participatory culture. New York, NY: New York University Press.

Jyh, W.S. (2009). Wired new learning: Blogging Malay literacy. Electronic Journal of Foreign Language Teaching, 6(1), 302-314.

Kwok, K. W. \& Chia, K. (2012). Memories at the margins: Chinese-educated intellectuals in Singapore. In Waterson, R. \& Kwok, K. W. (Eds.). Contestations of memory in Southeast Asia. Singapore: NUS Press.

Law, R. \& Cheung, S. (2010). The perceived destination image of Hong Kong as revealed in the travel blogs of mainland Chinese tourists. International Journal of Hospitality and Tourism Administration, 11(4), 303-327.

MacKinnon, R. (2008). Flatter world and thicker walls? Blogs, censorship and civic discourse in China. Public Choice, 134, 31-46.

Madianou, M. (2005). Mediating the nation: News, audiences and the politics of identity. London: UCL Press.

McCaughey, M., \& Ayers, M.D. (2003). Cyberactivism: Online activism in theory and practice. New York, NY: Routledge. 
Nardi, B. A., Schiano, D. J., Gumbrecht, M., \& Swartz, L. (2004). Why we blog. Communications of the ACM, 47(12), 41-46.

Ong, A. (2014, July 11). PMO responds to Zaobao editorial on Chinese language. The Straits Times.

Papacharissi, Z. (2002). The virtual space: The internet as a public space. New Media \& Society, 4(1), 9-27.

Sim, S.H. (2008). The use of blogging to enhance the learning of Chinese writing in secondary school students in Singapore. PhD Thesis, The University of Hong Kong.

Skoric, M., \& Ng, D. Y-Y. (2009). Bowling online, not alone: Online social capital and political participation in Singapore. Journal of Computer-Mediated Communication, 14(2), 414-433.

Soon, C. (2013). Going digital: Overcoming institutional and micro-structural constraints through technology use for collective action. eJournal of eDemocracy and Open Government, 5,2.

Soon, C. \& Cho, H. (2011). Flows of relations and communication among Singapore political bloggers and organizations: The networked public sphere approach. Journal of Information Technology and Politics, 8, 93-109.

Soon, C. \& Cho, H. (2014). OMGs! Offline-based movement organizations, online-based movement organizations and network mobilization: A case study of political bloggers in Singapore. Information, Communication and Society, 17(5), 537-559.

Soon, C. and Kluver, R. (2007). The Internet and online political communities in Singapore. Asian Journal of Communication, 17(3), 246-265.

Soon, C. \& Kluver, R. (2014). Uniting political bloggers in diversity: Collective identity and web activism. Journal of Computer-Mediated-Communication, Journal of Computer-Mediated-Communication,19(3), 500-515.

Soon, C. \& Tan, T.H. (2013, June). Corrosive speech: What can be done. Institute of Policy Studies. Available at http://lkyspp.nus.edu.sg/ips/wp-content/uploads/sites/2/2013/06/Report_ACM_CorrosiveSpeech-Report_120613-1.pdf

Tan, E. K. B. (2002). Reconceptualizing Chinese identity: The politics of Chineseness in Singapore. In Suryadinata (Ed.). Ethnic Chinese in Singapore and Malaysia: A dialogue between tradition and modernity. Singapore: Times Academic Press.

Tan, E. K. B. (2009). Chinese-Singaporean Identity: Subtle Change amidst Continuity. In Welsh, B., Chin, J., Mahizhnan, A., \& Tan, T. H. (Eds.). Impressions of the Goh Chok Tong Years in Singapore. Singapore: NUS Press-IPS.

Tan, C. (2006). Change and continuity: Chinese language policy in Singapore. Language Policy, 5, 41-62.

Tan, J.Q. (2001). Lim Chin Siong - A political life. In Tan J.Q. and Jomo K.S. (Eds.), Comet in our sky (pp.5697). KL, Malaysia: INSAN.

Tan, S. (2012). Language ideology in discourses of resistance to dominant hierarchies of linguistic worth: Mandarin Chinese and Chinese 'dialects' in Singapore, The Australian Journal of Anthropology, 23, 340-356. 
Tan, Y.H. \& Tan S-Ch. (2010). A metacognitive approach to enhancing Chinese language speaking skills with audioblogs. Australasian Journal of Educational Technology, 26(7), 1075-1089.

Trammell, K.D., Tarkowski, A., Hofmokl, J. \& Sapp, A.M. (2006). Rzeczpospolita blogów (republic of blog): Examining Polish bloggers through content analysis. Journal of Computer-Mediated Communication, $11,702-722$.

Tse, T. S. M. and Zhang, E. Y. L. (2012). Analysis of Blogs and Microblogs: A case study of Chinese bloggers sharing their Hong Kong travel experiences. Asia Pacific Journal of Tourism Research, 18(4), 314-329.

Ubaidullah, N.H., Mahadi, N. \& Lee, H.C. (2013). Exploring the educational benefits of blogs to help nonMalay pupils in Malay language learning. World of Computer Science and Information Technology Journal, 3(1), 20-25.

Yang, K. C. C. (2007). Factors influencing Internet users' perceived credibility of news-related blogs in Taiwan. Telematics and Informatics, 24(2), 69-85.

Zhao, W.Y. (2010，March 1). 身在异乡非异客新移民名博书写新加坡 (Translated: Immigrant bloggers in Singapore). Lianhe Zaobao.

\section{About the Authors}

\section{Carol Soon}

Dr. Carol Soon is Research Fellow at the Institute of Policy Studies. She completed her Ph.D. in the National University of Singapore and her research interests include digital engagement, digital deliberation and how individuals and organizations leverage new media to engender change. Her work has been published in the Journal of Computer-Mediated Communication, Information, Communication and Society, Asian Journal of Communication and Telematics and Information. In 2012, Dr. Soon was Visiting Research Fellow at the Asia Research Centre, Murdoch University, with support from the Australian Endeavour Award.

\section{Jui Liang Sim}

Jui Liang Sim is a research assistant at the Institute of Policy Studies, the National University of Singapore. He holds a Master of Mass Communication degree from the Nanyang Technological University. His research interests include media sociology, community arts and subcultural media. 